2. Perchinsky MJ, Lichtenstein SV, Tyers GF. Primary cardiac tumors: forty years' experience with 71 patients. Cancer. 1997;79:1809-15.

3. McManus B. Primary tumors of the heart. In: Bonow R, Mann D, Zipes D, Libby P, Braunwald E, eds. Braunwald's heart disease: a textbook of cardiovascular medicine. Philadelphia: Elsevier-Saunders; 2011. p. 1638-50.
4. Burke A, Virmani R. Tumors of the heart and the great vessels. Washington, DC: American Registry of Pathology; 1996.

5. Grandmougin D, Fayad G, Decoene C, Pol A, Warembourg H. Total orthotopic heart transplantation for primary cardiac rhabdomyosarcoma: factors influencing long-term survival. Ann Thorac Surg. 2001;71:1438-41.

\title{
Extra-anatomic pulmonary artery bypass for main pulmonary artery stenosis caused by neoplasm
}

\author{
Ryo Aeba, MD, ${ }^{\mathrm{a}}$ Hiroaki Nomori, MD, ${ }^{\mathrm{b}}$ and Ryohei Yozu, MD, ${ }^{\mathrm{a}}$ Tokyo, Japan
}

Currently, tumor-related pulmonary artery obstruction is most often treated with the percutaneous stenting technique $^{1-3}$; however, this technique is not indicated for patients with tumors situated in close proximity to the pulmonary valve. We present here such a case, that of a patient who had adenoid cystic carcinoma of trachea that recurred at pulmonary artery near the pulmonary valve and who underwent surgical management with an extra-anatomic pulmonary artery bypass.

\section{CLINICAL SUMMARY}

In November 2010, a 51-year-old man with a malignant thoracic tumor was referred to our hospital for management of pulmonary stenosis at the main pulmonary artery level as a result of tumoral invasion. The patient had previously had a tracheal adenoid cystic carcinoma diagnosed and treated with surgical resection and postoperative radiation therapy (56 Gy) in 1999 at another hospital. The malignant tumor was not curable, and the patient had been followed up thereafter. In October 2010, the patient reported shortness of breath while walking. Transthoracic echocardiography demonstrated a mass causing compression of the main pulmonary artery immediately $(<2 \mathrm{~mm})$ distal to the sinotubular junction of the pulmonary valve. Continuous-wave Doppler echocardiography showed a peak systolic gradient of $85 \mathrm{~mm} \mathrm{Hg}$ in the pulmonary artery at the site of compression. The right ventricle was hypertensive and compressed the left ventricle. Cardiac catheterization also showed right ventricular hypertension at 103/11 $\mathrm{mm} \mathrm{Hg}$.

From the Divisions of Cardiovascular Surgery ${ }^{\mathrm{a}}$ and General Thoracic Surgery, ${ }^{\mathrm{b}}$ Keio University, Tokyo, Japan.

Disclosures: Authors have nothing to disclose with regard to commercial support.

Received for publication March 2, 2012; accepted for publication April 4, 2012; available ahead of print May 2, 2012.

Address for reprints: Ryo Aeba, MD, Division of Cardiovascular Surgery, Keio University, 35 Shinanomachi, Shinjuku, Tokyo 160-8582, Japan (E-mail: aebajp@ gmail.com).

J Thorac Cardiovasc Surg 2012;144:e10-1

0022-5223/\$36.00

Copyright (C) 2012 by The American Association for Thoracic Surgery doi:10.1016/j.jtcvs.2012.04.005
In February 2011, the patient underwent an open surgical intervention through a midline sternotomy. The mass was firmly adherent to the ascending aortic wall and pericardium. Cardiopulmonary bypass was established. Under the conditions of an empty, beating heart, the pulmonary trunk was opened transversely at the level of the sinotubular junction. Another pulmonary arteriotomy was created in the anterior aspect of the right branch pulmonary artery, between the ascending aortic and the superior vena caval crossings. A polytetrafluoroethylene tube graft $18 \mathrm{~mm}$ in diameter (W.L. Gore \& Associates, Flagstaff, Ariz) was tailored and interposed between the 2 pulmonary arteriotomies in an extra-anatomic manner, immediately anterior to the ascending aorta.

The patient stayed in the intensive care unit for 1 day after the operation. His recovery was uneventful, and he was free

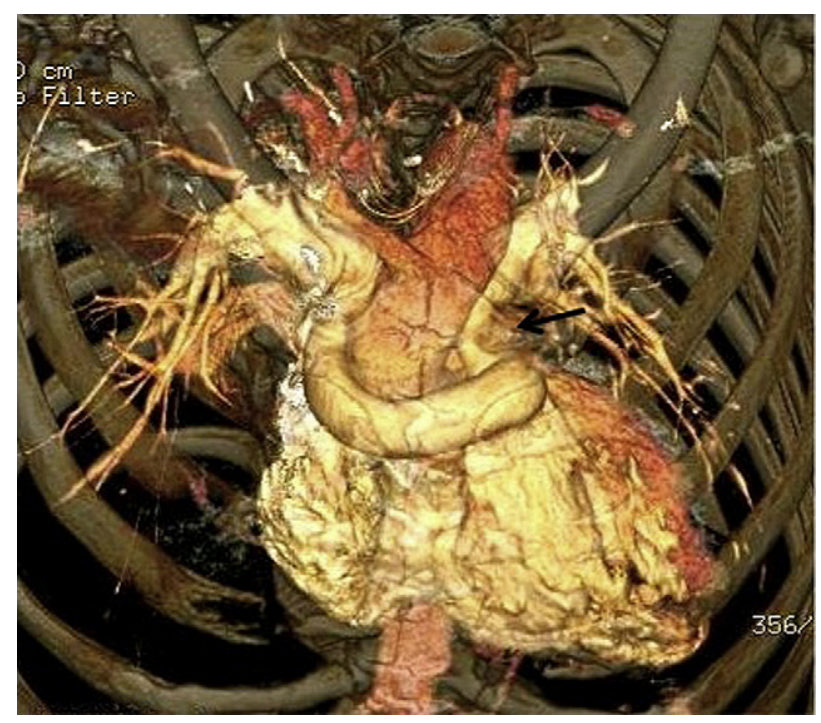

FIGURE 1. Contrast-enhanced multidetector computed tomographic scan 2 weeks after surgery. Three-dimensional volume-rendered image demonstrates an unobstructed tube graft with an extra-anatomic position, bypassing the main pulmonary artery obstruction caused by the tumor (arrow). 
of symptoms soon after discharge. Transthoracic echocardiography with continuous-wave Doppler at the outpatient clinic after 3 months demonstrated normal wall motion recovery of the interventricular septum, no pulmonary regurgitation, and an indetectable peak systolic gradient. Contrast-enhanced multidetector computed tomography showed unobstructed tube graft patency (Figure 1). Pulmonary blood flow scan showed a right-to-left flow ratio of 56:44. The patient continues to do well 12 months after the operation.

\section{DISCUSSION}

Patients with tumors involving the heart and great arteries are usually not considered for surgical treatment because of their poor prognosis. Patients with adenoid cystic carcinoma of upper airway, however, can survive long even after palliative treatment because tumor growth is indolent. ${ }^{4}$ Pulmonary trunk obstruction by a malignant neoplasm is a rare but potentially lethal condition. Increasing numbers of cases have been reported of patients undergoing management with the percutaneous catheter stenting technique, which is not only highly effective but also minimally invasive and therefore should be considered as the standard option in the current era. ${ }^{1-3}$ In this case, however, that technique was not indicated because of the close proximity of the pulmonary valve. Surgical tumor resection is another option of choice in such cases, and this technique also requires cardiopulmonary bypass support. ${ }^{5}$ The use of resection in our patient necessitated combined aortic reconstruction under a condition of induced cardiac arrest, which also can increase the risk of early obstruction recurrence with local tumor reexpansion. To the best of our knowledge, this is the first report describing the use of this technique for palliative surgical treatment of an obstructed main pulmonary artery. Our observations show that pulmonary trunk obstruction with pulmonary neoplasm invasion close to the pulmonary valve does not necessarily constitute an unmanageable condition.

\section{References}

1. Müller-Hülsbeck S, Bewig B, Schwarzenberg H, Heller M. Percutaneous placement of a self-expandable stent for treatment of a malignant pulmonary artery stenosis. Br J Radiol. 1998;71:785-7.

2. Hirota S, Matsumoto S, Yoshikawa T, Maruta T, Sugimoto K, Sugimura K. Stent placement for malignant pulmonary artery structure. Cardiovasc Intervent Radiol. 2000;23:242-4.

3. Meckel S, Buitrago-Téllez C, Herrmann R, Jacob AL. Stenting for pulmonary artery stenosis due to a recurrent primary leiomyosarcoma. J Endovasc Ther. 2003; 10:141-6.

4. Maziak DE, Todd TR, Keshavjee SH, Winton TL, Van Nostrand P, Pearson FG Adenoid cystic carcinoma of the airway: thirty-two-year experience. $J$ Thorac Cardiovasc Surg. 1996;112:1522-32.

5. Mayer E, Kriegsmann J, Gaumann A, Kauczor HU, Dahm M, Hake U, et al. Surgical treatment of pulmonary artery sarcoma. J Thorac Cardiovasc Surg. 2001; 121:77-82. 